\title{
COMUNICAÇÃO
}

\section{CONDIÇÕES HIGIÊNICO-SANITÁRIAS DE UMA INDÚSTRIA DE PROCESSAMENTO DE CONSERVAS DE POLPA DE PEQUI NA REGIÃO NORTE DO ESTADO DE MINAS GERAIS}

\author{
Hygienic and sanitary conditions of a pequi pulp preserve industry in the northern \\ area of the state of Minas Gerais
}

\author{
Luiz Carlos Ferreira', Roberto Gonçalves Junqueira²
}

\begin{abstract}
RESUMO
Foi realizada uma avaliação das condições higiênico-sanitárias de uma indústria de processamento de conservas de polpa de pequi da região norte do estado de Minas Gerais. Foram avaliadas as microbiotas da polpa do fruto do pequizeiro (Caryocar brasiliense Camb.) in natura, da polpa recém-retirada, da polpa armazenada após o branqueamento, das mãos dos manipuladores, das superfícies de manipulação, do ambiente e da água usada no processamento, considerando-se a quantificação de bactérias mesófilas aeróbias, bolores e leveduras, enterobactérias, coliformes totais e coliformes a $45^{\circ} \mathrm{C}$, além da pesquisa de bactérias potencialmente patogênicas, tais como Salmonella spp. e Staphylococcus coagulase positiva. Em proporções variáveis, verificou-se a presença de microrganismos deterioradores, patógenos e daqueles indicadores de contaminação de origem fecal. Demonstrou-se ineficiência dos procedimentos de higiene pessoal e de sanitização das superfícies de manipulação. A água usada pela indústria não estava em conformidade com os padrões bacteriológicos de potabilidade estabelecidos pela legislação brasileira. Os resultados obtidos alertam para a necessidade de implementação de um sistema de monitoramento microbiológico na área de processamento das conservas de polpa de pequi, incluindo equipamentos, utensílios, superfícies, ar, água e os manipuladores. A implementação das Boas Práticas de Fabricação é uma ferramenta essencial a ser utilizada pela indústria avaliada para garantir a segurança do produto final.
\end{abstract}

Termos para indexação: Caryocar brasiliensis, avaliação microbiológica, riscos microbiológicos, boas práticas de fabricação, pequi.

\section{ABSTRACT}

An evaluation of the hygienic-sanitary conditions of a processing industry of pequi (Caryocar brasiliense Camb.) pulp preserve located in the northern area of the state of Minas Gerais was accomplished. The microbial load of the pulp of the fruit in natura, the freshly detached pulp, the pulp stored after the bleaching, hands of handlers, surfaces in contact with the pulp, air, and water were evaluated. The following analysis were carried out: total aerobic mesophilic bacteria, yeast and mould, enterobacteria, total coliform and coliform bacteria at $45^{\circ} \mathrm{C}$, as well as the research of bacteria potentially pathogenic, such as Salmonella spp. and Staphylococcus coagulase positive. In variable proportions, the presence of indicators of fecal contamination, pathogenic and spoilage microorganisms were verified. Inefficiency of the procedures of personal hygiene and sanitization of the manipulation surfaces were demonstrated. The water used by the industry was in non-conformance with the bacteriological standards required by the Brazilian legislation. The results alert for the need of implementation of a microbiologic monitoring system in the processing area of pequi pulp preserves, including equipments, utensils, surfaces, air, water and handlers. The implementation of Good Manufacturing Practices will be an essential tool for the evaluated industry to guarantee the safety of the final product.

Index terms: Caryocar brasiliensis, microbiological evaluation, microbial hazards, good manufacturing practices.

(Recebido em 18 de julho de 2006 e aprovado em 3 de abril de 2008)

O pequizeiro (Caryocar brasiliense Camb.) é uma espécie nativa do cerrado brasileiro (ARAÚJO, 1995) e o extrativismo de seu fruto é de grande importância para a alimentação e a renda das populações do norte do estado de Minas Gerais (DOMBROSKI, 1997; MELO JÚNIOR et al., 2004). A produção de pequi no estado de Minas Gerais, no ano de 2005 foi de $327.895 \mathrm{~kg}$, segundo dados da central de abastecimento do estado (CEASAMINAS, 2006). No norte de Minas Gerais, a extração e comercialização do pequi podem representar até $50 \%$ da renda anual dos trabalhadores locais (LOPES et al., 2003; POZO, 1997)

'Doutor em Ciência de Alimentos, Professor - Departamento de Fitotecnia - Instituto de Ciências Agrárias/ICA - Universidade Federal de Minas Gerais/ UFMG - Avenida Universitária, 1000 - Universitário - Cx. P. 135 - 39404-006 - Montes Claros, MG - luizcarlosf@ufmg.br 2Doutor em Bioquímica e Imunologia, Professor - Departamento de Alimentos - Faculdade de Farmácia/FAFAR - Universidade Federal de Minas Gerais/ UFMG - Avenida Carlos, 6627 -Pampulha -31270-901 - junkeira@dedalus.lcc.ufmg.br 
O pequi é utilizado pelas populações rurais para sua subsistência e pelas indústrias de derivados, principalmente as conservas de polpa. Siqueira et al. (1997) recomendam para produção de conservas de polpa do pequi o seguinte roteiro de processamento: limpeza dos frutos, obtenção das sementes, seleção e classificação, lavagem, branqueamento, resfriamento, acondicionamento, adição de salmoura, exaustão, fechamento e tratamento térmico.

O consumo do pequi tem sido incentivado por políticas públicas (MINAS GERAIS, 2002). A produção de um de seus principais derivados, a conserva de polpa, geralmente não exige muita sofisticação de equipamentos e instalações (ALMEIDA et al., 1987) e muitas vezes seu processamento tem um caráter puramente artesanal. A carência de assistência técnica qualificada para a industrialização das conservas pode originar produtos sem garantia de segurança microbiológica, com conseqüências danosas aos consumidores.

É reconhecido mundialmente que as Boas Práticas de Fabricação (BPF) são uma ferramenta essencial para se garantir a inocuidade e a segurança dos alimentos consumidos. As BPF se constituem em um conjunto de princípios e regras para o correto manuseio de alimentos, abrangendo desde as matérias-primas até o produto final (OPAS, 2001). Para monitoração das BPF, a análise microbiológica é fundamental e a amostragem deve corresponder aos pontos críticos de contaminação (APHA, 1992; CUNHA et al., 2000).

Torrezan et al. (2000) afirmam que a contaminação microbiana de frutas industrializadas é proveniente principalmente do ar de áreas de processamento, da água usada na indústria, de superfícies de contato com o alimento e das condições higiênico-sanitárias dos manipuladores. Durante a produção, o ar pode contaminar os alimentos com patógenos ou microrganismos deterioradores presentes em aerossóis (SALUSTIANO et al., 2003). Toda a água que entra em contato com o alimento ou com superfícies de manipulação dever ser potável e de qualidade sanitária adequada. Independente de sua fonte, se de rede pública ou particular, o abastecimento de água deve ser freqüentemente monitorado (OPAS, 2001). As superfícies de processamento do alimento podem suportar o crescimento de microrganismos e tornar-se uma fonte de contaminação (SALUSTIANO et al., 2003). Certos microrganismos, incluindo alguns patógenos, podem se adaptar a condições rigorosas ao formarem biofilmes (KUMAR \& ANAND, 1998). Quanto aos manipuladores, eles podem ser portadores de formas vegetativas de bactérias patogênicas. Segundo dados da Organização Mundial da Saúde, até $26 \%$ dos surtos de doenças de origem alimentar são vinculados aos manipuladores e, portanto, o seu treinamento em segurança alimentar é uma das intervenções mais críticas na prevenção de doenças de origem alimentar (WHO, 2006).

Objetivou-se, neste trabalho, avaliar as condições higiênico-sanitárias no processamento de conservas de polpa de pequi em uma indústria da região norte do estado de Minas Gerais, determinando as condições microbiológicas da matéria-prima, das mãos dos manipuladores, das superfícies de manipulação, do ambiente e da água usada durante o processamento.

Foram coletadas, em uma indústria de processamento de conservas de polpa de pequi da região norte do estado de Minas Gerais, amostras da polpa do pequi in natura, polpa do pequi recém-retirada e polpa armazenada após o branqueamento. As amostras foram coletadas no local de processamento e transportadas, em caixa isotérmica até o laboratório. Foram também analisadas, as mãos dos manipuladores, superfícies de manipulação, ambiente e água utilizada dentro da indústria.

Foram realizadas as contagens de mesófilos aeróbios, bolores e leveduras, enterobactérias, coliformes totais, coliformes a $45^{\circ} \mathrm{C}$, pesquisa de Salmonella spp., pesquisa e contagem de Staphylococcus coagulase positiva, segundo metodologias descritas no Compendium of Methods for the Microbiological Examination of Foods (APHA, 1992). Os experimentos foram conduzidos com três repetições para cada determinação microbiológica.

A contagem de mesófilos aeróbios foi realizada por espalhamento em superfície de ágar Tripticase de Soja (TSA - Difco, Sparks, USA) e incubação a $35^{\circ} \mathrm{C}$ por 24 a $48 \mathrm{~h}$. Bolores e leveduras foram contados por espalhamento em superfície de ágar Batata Dextrose (PDA - Oxoid, Basingstoke, UK) acidificado e incubado a $25^{\circ} \mathrm{C}$ por 3 a 5 dias. A contagem de enterobactérias foi feita por espalhamento em superfície de ágar MacConkey (Acumedia, Lansing, USA) e incubação a $37^{\circ} \mathrm{C}$ por 24 a 48 h. Para coliformes totais e coliformes a $45^{\circ} \mathrm{C}$ foi utilizada a técnica do Número Mais Provável (NMP). A contagem e pesquisa de Staphylococcus coagulase positiva foi realizada por espalhamento em superfície de ágar BairdParker (Merck, Darmstadt, Germany) suplementado com telurito de potássio e gema de ovo e incubação a $37^{\circ} \mathrm{C}$ por 24 a 48 h, sendo a confirmação das colônias típicas feita por meio da coloração de Gram e do teste de coagulase. A pesquisa de Salmonella spp. foi feita com préenriquecimento em Água Peptonada Tamponada (APT Acumedia, Baltimore, USA) a $37^{\circ} \mathrm{C}$ por $18 \mathrm{~h}$, seguida de enriquecimento seletivo nos caldos Tetrationato (TT Acumedia, Lansing, USA) e Selenito Cistina (SC Acumedia, Lansing, USA) a $37^{\circ} \mathrm{C}$ por $24 \mathrm{~h}$. O isolamento de Salmonella spp. foi realizado em ágar Xilose Lisina 
Desoxicolato (XLD - Acumedia, Lansing, USA), ágar Hectoen (HE - Acumedia, Lansing, USA) e ágar Bismuto Sulfito (BS - Acumedia, Lansing, USA) a $37^{\circ} \mathrm{C}$ por 24 a 48 h. As colônias suspeitas foram inoculadas em tubos inclinados de ágar Lisina Ferro (LIA - Acumedia, Lansing, USA) e ágar Tríplice Açúcar Ferro (TSI - Acumedia, Lansing, USA), que foram incubados por $24 \mathrm{~h}$ a $37^{\circ} \mathrm{C}$. Os isolados que apresentaram reações características de Salmonella spp. foram submetidos à identificação bioquímica com os testes de produção de indol, fermentação de lactose, fermentação de dulcitol, catalase, fermentação do malonato, vermelho de metila (VM), Voges-Proskauer (VP) e utilização de citrato. Os isolados que apresentaram resultado característico para Salmonella spp. nos testes bioquímicos foram avaliados por teste sorológico, com antisoro $\mathrm{H}$ polivalente (Difco, Sparks, USA).

As amostras de polpa do pequi in natura foram retiradas em laboratório, assepticamente, a partir de frutos coletados na indústria. As amostras de polpa recém-retirada e de polpa armazenada após o branqueamento foram coletadas e transportadas em frascos estéreis. Todas as amostras de polpa foram homogeneizadas em stomacher por 2 min e em seguida foram feitas as contagens de mesófilos aeróbios, bolores e leveduras, enterobactérias, Staphylococcus coagulase positiva, coliformes totais, coliformes a $45^{\circ} \mathrm{C}$ e pesquisa de Salmonella spp.

Foram coletadas 12 amostras das mãos dos manipuladores e três amostras de superfícies de manipulação pela técnica do swab descrita pela American Public Health Association (APHA, 1992). Nas mãos, a amostragem correspondeu à superfície da palma e das bordas das mãos, percorrida com $s w a b$ estéril por três vezes consecutivas. Para amostragem das superfícies de processamento, foi utilizado $s w a b$ aplicado a um ângulo de $30^{\circ}$ de contato com a superfície, percorrendo uma área de $100 \mathrm{~cm}^{2}$, por três vezes consecutivas. Após a coleta do material das mãos e das superfícies, cada $s w a b$ foi quebrado descartando a parte manuseada, colocando-os finalmente em tubos de água peptonada tamponada. Nas amostras coletadas nas mãos, foi avaliada a presença de Salmonella spp., Staphylococcus coagulase positiva e coliformes a 45 ${ }^{\circ} \mathrm{C}$, enquanto que nas superfícies foi feita a contagem de mesófilos aeróbios, bolores e leveduras, enterobactérias, Staphylococcus coagulase positiva, coliformes totais, coliformes a $45^{\circ} \mathrm{C}$ e pesquisa de Salmonella spp.

A qualidade do ar das áreas de processamento foi avaliada utilizando-se a técnica de sedimentação simples em placa de Petri, descrita no Compendium of Methods for the Microbiological Examination of Foods (APHA, 1992). Foram utilizadas placas com ágar BDA, ágar TSA e ágar MacConkey, para contagem de bolores e leveduras, mesófilos aeróbios e enterobactérias, respectivamente. As placas foram distribuídas pela área de processamento e expostas por 15 min. Depois de fechadas, as placas foram incubadas a $35^{\circ} \mathrm{C} /$ 24-48 h para contagem de mesófilos aeróbios, $25^{\circ} \mathrm{C} / 3-5$ dias para bolores e leveduras e $37^{\circ} \mathrm{C} / 24-48 \mathrm{~h}$ para enterobactérias. Os resultados foram expressos em UFC/ $\mathrm{cm}^{2} /$ semana. A partir de cada amostra de água coletada dentro da indústria determinou-se o NMP de bactérias do grupo coliformes totais e coliformes a $45^{\circ} \mathrm{C}$.

$\mathrm{Na}$ Tabela 1, estão expressos os resultados das análises microbiológicas realizadas nas amostras de polpa do pequi in natura, polpa recém-retirada e polpa armazenada após o branqueamento. Nas amostras da polpa in natura, as contagens foram da ordem $10^{3} \mathrm{UFC} / \mathrm{g}$ para bactérias mesófilas aeróbias e para bolores e leveduras. As baixas contagens na polpa in natura de enterobactérias, Staphylococcus coagulase positiva, coliformes totais e coliformes a $45^{\circ} \mathrm{C}$ sugerem que esses grupos de microrganismos não fazem parte da microbiota nativa do fruto do pequizeiro.

As amostras de polpa recém-retiradas apresentaram contagens de mesófilos aeróbios, bolores e leveduras, enterobactérias e Staphylococcus coagulase positiva, em média da ordem de $10^{5}, 10^{7}, 10^{4}$ e $10^{4} \mathrm{UFC} / \mathrm{g}$, respectivamente. Quanto aos coliformes totais e coliformes a $45^{\circ} \mathrm{C}$, foi encontrada uma contagem média de $>10^{3}$ e 10 $\mathrm{NMP} / \mathrm{g}$, respectivamente. Em relação à polpa armazenada após o branqueamento, as contagens médias desses grupos de microrganismos foram sempre inferiores ao da polpa recém-retirada. Foi detectada a presença de Salmonella spp. em todas as amostras de polpa recémretirada e em 1/3 das amostras armazenadas após o branqueamento, porém, nenhuma das amostras da polpa do pequi in natura apresentou esse microrganismo.

Foi verificada a presença de Salmonella spp. em 33 $\%$ das amostras das mãos dos manipuladores, estando também presente Staphylococcus coagulase positiva e coliformes a $45{ }^{\circ} \mathrm{C}$ na frequiência de $83 \%$ e $58 \%$ das amostras, respectivamente (Tabela 2 ).

Nas superfícies de manipulação, a contagem microbiana foi em média de $10^{4} \mathrm{UFC} / \mathrm{cm}^{2}$ de mesófilos aeróbios, $10^{5} \mathrm{UFC} / \mathrm{cm}^{2}$ de bolores e leveduras, $10^{4} \mathrm{UFC} /$ $\mathrm{cm}^{2}$ de enterobactérias e $10^{2} \mathrm{UFC} / \mathrm{cm}^{2}$ de Staphylococcus coagulase positiva. Foram encontradas também bactérias coliformes nas superfícies (Tabela 3). Na avaliação do ar ambiental da indústria foram observadas contagens médias de $10^{3}, 10^{2}$ e $<10 \mathrm{UFC} / \mathrm{cm}^{2} /$ semana para mesófilos aeróbios, bolores e leveduras e enterobactérias, respectivamente. Demonstrou-se, também, que todas as amostras da água utilizada dentro da indústria estavam contaminadas por coliformes totais e coliformes termotolerantes (Tabela 3). 
Tabela 1 - Análise microbiológica das amostras de polpa de pequi in natura, polpa recém- retirada e polpa armazenada após o branqueamento.

\begin{tabular}{|c|c|c|c|}
\hline $\begin{array}{c}\text { Análise } \\
\text { Microbiológica }\end{array}$ & $\begin{array}{c}\text { Polpa in natura } \\
\text { log (UFC/g) }\end{array}$ & $\begin{array}{c}\text { Polpa recém-retirada } \\
\log (\mathrm{UFC} / \mathrm{g})\end{array}$ & $\begin{array}{c}\text { Polpa armazenada após o } \\
\text { branqueamento } \\
\log (\mathrm{UFC} / \mathrm{g})\end{array}$ \\
\hline Mesófilos aeróbios & $2,88 \mathrm{UFC} / \mathrm{g}$ & $5,26 \mathrm{UFC} / \mathrm{g}$ & $3,92 \mathrm{UFC} / \mathrm{g}$ \\
\hline Bolores e leveduras & $3,17 \mathrm{UFC} / \mathrm{g}$ & 6,64 UFC /g & $3,62 \mathrm{UFC} / \mathrm{g}$ \\
\hline Enterobactérias & $<1,00 \mathrm{UFC} / \mathrm{g}$ & $3,96 \mathrm{UFC} / \mathrm{g}$ & 2,77 UFC /g \\
\hline Coliformes totais & $<0,48 \mathrm{NMP} / \mathrm{g}$ & $>3,04 \mathrm{NMP} / \mathrm{g}$ & $1,41 \mathrm{NMP} / \mathrm{g}$ \\
\hline Coliformes a $45^{\circ} \mathrm{C}$ & $<0,49 \mathrm{NMP} / \mathrm{g}$ & $1,23 \mathrm{NMP} / \mathrm{g}$ & $<0,48 \mathrm{NMP} / \mathrm{g}$ \\
\hline $\begin{array}{l}\text { Staphylococcus } \\
\text { coagulase positive }\end{array}$ & $<1,00 \mathrm{UFC} / \mathrm{g}$ & $<3,63 \mathrm{UFC} / \mathrm{g}$ & $<1,00 \mathrm{UFC} / \mathrm{g}$ \\
\hline $\begin{array}{l}\text { Salmonella spp. } \\
\text { (Presença/Amostras) }\end{array}$ & $0 / 3$ & $3 / 3$ & $1 / 3$ \\
\hline
\end{tabular}

Tabela 2 - Análise microbiológica das amostras coletadas das mãos dos manipuladores.

\begin{tabular}{lcl}
\hline \multicolumn{1}{c}{ Análise Microbiológica } & Amostras Positivas* & $(\%)$ \\
\hline Coliformes a $45^{\circ} \mathrm{C}$ & 7 & 58,3 \\
Staphylococcus coagulase positiva & 10 & 83,3 \\
Salmonella spp. & 4 & 33,3 \\
\hline
\end{tabular}

*Obtidas das mãos de 12 manipuladores.

Tabela 3 - Análise microbiológica de amostras das superfícies de manipulação, do ambiente e da água utilizada no processamento.

\begin{tabular}{lccc}
\hline \multicolumn{1}{c}{$\begin{array}{c}\text { Análise } \\
\text { Microbiológica }\end{array}$} & $\begin{array}{c}\text { Superfícies de Manipulação } \\
\log \left(\mathrm{UFC} / \mathrm{cm}^{2}\right)\end{array}$ & $\begin{array}{c}\text { Ambiente } \\
\log \left(\mathrm{UFC} / \mathrm{cm}^{2} / \mathrm{semana}\right)\end{array}$ & $\begin{array}{c}\text { Água } \\
\log (\mathrm{NM} / \mathrm{mL})\end{array}$ \\
\hline Mesófilos aeróbios & 4,02 & 2,77 & $\mathrm{nd}$ \\
Bolores e leveduras & 4,84 & 2,15 & $\mathrm{nd}$ \\
Enterobactérias & 3,6 & $<1,00$ & $\mathrm{nd}$ \\
Coliformes totais & 3,04 & $\mathrm{nd}$ & 3,04 \\
Coliformes a $45^{\circ} \mathrm{C}$ & 1,33 & $\mathrm{nd}$ & 1,55 \\
$\begin{array}{l}\text { Staphylococcus } \\
\text { coagulase positiva }\end{array}$ & 2,2 & $\mathrm{nd}$ & $\mathrm{nd}$ \\
$\begin{array}{l}\text { Salmonella } \text { spp. } \\
\text { (Presença/Amostras) }\end{array}$ & $3 / 3$ & & $\mathrm{nd}$ \\
\hline
\end{tabular}

nd: não determinado.

Embora a enumeração de microrganismos mesófilos aeróbios geralmente não represente um critério de rejeição do produto final, uma contagem alta desses microrganismos nos produtos reflete condições inadequadas da matériaprima, processamento e armazenamento (ICMSF, 2001). Além disso, uma alta carga microbiana pode mascarar a detecção de patógenos mesófilos, sendo maior a probabilidade de ocorrência desses microrganismos (FALCÃO et al., 1983). A contagem elevada de bolores e leveduras também é indicativa de condições higiênicas insatisfatórias, podendo comprometer a vida de prateleira do produto final (BRUNO et al., 2005). O crescimento de fungos pode elevar o $\mathrm{pH}$ de produtos vegetais ácidos para valores favoráveis ao crescimento de bactérias patogênicas (BRUNO et al., 2005). 
A detecção de Staphylococcus em alimentos está relacionada com manipulação inadequada durante o processamento (RODRIGUES et al., 2003; BRUNO et al., 2005). As espécies de Staphylococcus são os microrganismos contaminantes mais comuns disseminadas por manipuladores de alimentos (ANDRADE et al., 2003; APHA, 1992).

A presença de Salmonella spp., por ser potencialmente capaz de provocar infecção alimentar, caracteriza a polpa recém-retirada e a polpa armazenada após o branqueamento como impróprias para o consumo. A Legislação Brasileira estabelece ausência de Salmonella spp. em alimentos (BRASIL, 2001b). Pinto et al. (2004) fazem um alerta quanto ao tempo de geração de Salmonella spp., que varia de 24 a 34 min, podendo atingir números elevados, mesmo que a contaminação inicial tenha sido baixa. No Brasil, foram registrados 192 surtos de doenças de origem alimentar nos anos de 1996 e de 1998 a 2000, com 12.188 enfermos e 3 mortes, sendo a salmonelose responsável pela maioria, com incidência em 76,56\% dessas ocorrências (PINHEIRO et al., 2005).

A presença de microrganismos patogênicos nas mãos dos manipuladores e nas superfícies de manipulação é de grande importância para segurança alimentar, devido à possibilidade de transferência dos mesmos para os alimentos (ALMEIDA et al., 1995). Um manipulador de alimentos é capaz de disseminar de 20 a 70 microrganismos por minuto (SALUSTIANO et al., 2003).

A baixa contagem de enterobactérias no ar da área de processamento sugere que esses microrganismos não sobrevivem bem nos aerossóis. Entretanto, essa baixa contagem verificada pode ser explicada pela possibilidade desses microrganismos terem sido afetados pelo meio seletivo utilizado na técnica de contagem, uma vez que os mesmos, segundo a APHA (1992), podem estar estressados nos aerossóis.

Todas as amostras analisadas da água usada na indústria estavam com número elevado de bactérias coliformes totais e coliformes a $45^{\circ} \mathrm{C}$. De acordo com a Portaria ${ }^{\circ} 1469$, de 29 de dezembro de 2000 do Ministério da Saúde (BRASIL, 2001a), o padrão estabelecido em relação à água para consumo humano é de ausência de coliformes totais e coliformes termotolerantes, em $100 \mathrm{~mL}$ de amostra. Sabe-se que os coliformes totais são bons indicadores das condições sanitárias dos alimentos, sendo que os coliformes a $45^{\circ} \mathrm{C}$ são considerados melhores indicadores de contaminação de origem fecal do que os coliformes totais, por serem específicos de fezes humanas e de animais de sangue quente, indicando condições propícias para o aparecimento também de patógenos intestinais (FALCÃO et al., 1983; PINHEIRO et al., 2005). A presença de microrganismos patogênicos na água é decorrente da poluição por fezes humanas e de animais, provenientes de águas residuárias urbanas e rurais (AMARAL et al., 1994).

$\mathrm{Na}$ indústria de alimentos, a qualidade da água, a higienização das superfícies e utensílios, a qualidade do ar ambiental, bem como o treinamento dos manipuladores são de fundamental importância para a segurança e a qualidade microbiológica dos produtos finais. Foi verificada deficiência de informações quanto à qualidade da água, a utilização de cloro e as técnicas de sanitização. A água utilizada não era de rede pública, mas de poço particular. Os poços mantidos de maneira apropriada podem fornecer água de qualidade sanitária adequada, no entanto, são mais susceptíveis à contaminação do que a água de fontes públicas (OPAS, 2001).

A inocuidade das conservas ácidas de polpa de pequi não pode ser garantida apenas pelo seu $\mathrm{pH}$. NguyenThe \& Carlin (1994) relatam a sobrevivência e o crescimento de Salmonella typhimurium em sucos de algumas variedades de maçãs, em pH 3,68. Beuchat (2002) faz referência à adaptação de microrganismos patogênicos às condições de estresse ambiental, como a sobrevivência em pH muito ácido em alimentos.

A contaminação durante o processamento das conservas de polpa de pequi ocorre principalmente durante a retirada da polpa, quando microrganismos presentes na superfície do fruto in natura ou nas mãos dos manipuladores passam para a polpa. Fantuzzi et al. (2004) afirmam que o manuseio em condições inadequadas de higiene, os danos causados nos tecidos vegetais e a higienização inadequada de superfícies e equipamentos, contribui para o aumento da população microbiana nos vegetais.

Os resultados da avaliação das condições higiênico-sanitárias da indústria de processamento de conservas de polpa de pequi alertam para a necessidade de implementação de um sistema de monitoramento microbiológico na área de processamento das conservas de polpa de pequi, incluindo equipamentos, utensílios, superfícies, ar, água e os manipuladores. A implementação de Boas Práticas de Fabricação será uma ferramenta fundamental a ser utilizada pela indústria avaliada para garantir a segurança do produto final.

As amostras analisadas de polpa armazenadas para serem utilizadas na produção de conservas de polpa de pequi não apresentam segurança alimentar, visto que foi detectada a presença de Salmonella spp. Além disso, as elevadas contagens de bolores e leveduras, aeróbios 
mesófilos, enterobactérias e Staphylococcus coagulase positiva na polpa recém-retirada e superfícies de manipulação, assim como a presença de Salmonella spp., coliformes a $45^{\circ} \mathrm{C}$ e Staphylococcus coagulase positiva nas mãos dos manipuladores indica deficiência nos procedimentos de higiene, durante o processamento.

\section{REFERÊNCIAS BIBLIOGRÁFICAS}

ALMEIDA, R. C. C.; KUAYE, A. Y.; SERRANO, A. M.; ALMEIDA, P. F. Avaliação e controle da qualidade microbiológica de mãos de manipuladores de alimentos. Revista de Saúde Pública, São Paulo, v. 29, n. 4, p. 290294, ago. 1995.

ALMEIDA, S. P.; SILVA, J. A.; RIBEIRO, J. F. Aproveitamento alimentar de espécies nativas dos cerrados. Planaltina: Embrapa-CPAC, 1987. 83 p.

AMARAL, L. A.; RODRIGUES JÚNIOR, O. D.; NAVES FILHO, A.; ALEXANDRE, A. V. Avaliação da qualidade higiênico-sanitária da água de poços rasos localizados em uma área urbana: utilização de colifagos em comparação com indicadores bacterianos de poluição fecal. Revista de Saúde Pública, São Paulo, v. 28, n. 5, p. 345-348, out. 1994.

ANDRADE, N. J.; SILVA, R. M. M.; BRABES, K. C. S. Avaliação das condições microbiológicas em unidades de alimentação e nutrição. Ciência Agronômica, Lavras, v. 27, n. 3, p. 590-596, maio/jun. 2003.

APHA. Compendium of methods for the microbiological examination of foods. 3. ed. Washington, DC, 1992. 1219 p.

ARAÚJO, F. D. A review of Caryocar brasiliense (Caryocaraceae): an economically valuable of central Brazilian Cerrados. Economic Botany, New York, v. 49, p. 40-48, Jan./Mar. 1995.

BEUCHAT, L. R. Ecological factors influencing survival and growth of human pathogens on raw fruits and vegetables. Microbes and Infection, Amsterdam, n. 4, p. 413-423, Apr. 2002.

BRASIL. Ministério da Saúde. Portaria n. 1469, de 29 de dezembro de 2000. Procedimentos e responsabilidades relativos ao controle e vigilância da qualidade da água para consumo humano e seu padrão de potabilidade. Brasília, DF, 2001a.
BRASIL. Ministério da Saúde. Agência Nacional de Vigilância Sanitária. Resolução - RDC n. 12, de 2 de janeiro de 2001. Estabelece padrões microbiológicos de alimentos. Brasília, DF, 2001b.

BRUNO, L. M.; QUEIROZ, A. A. M.; ANDRADE, A. P. C.; VASCONCELOS, N. M.; BORGES, M. F. Avaliação microbiológica de hortaliças e frutas minimamente processadas comercializadas em fortaleza (CE). Boletim CEPPA, Curitiba, v. 23, n. 1, p. 75-84, jan./jun. 2005.

\section{CENTRAIS DE ABASTECIMENTO DE MINAS} GERAIS. Acompanhamento da oferta de produtos por estado do país: Minas Gerais, de janeiro/2005 a fevereiro/ 2006. Belo Horizonte, 2006.

CUNHA, V. A.; BASTOS, M. S. R.; FEITOSA, T.; OLIVEIRA, M. E. B.; MUNIZ, C. R. Diagnóstico das condições higiênico-sanitárias dos equipamentos utilizados em três fábricas de polpa de fruta congelada da região metropolitana de Fortaleza. Boletim CEPPA, Curitiba, v. 18, n. 2, p. 171-176, jul./dez. 2000.

DOMBROSKI, J. L. D. Estudos sobre a propagação do pequizeiro (Caryocar brasiliense Camb.). 1997. $80 \mathrm{f}$. Dissertação (Mestrado em Agronomia/Fisiologia Vegetal) - Universidade Federal de Lavras, Lavras, 1997.

FALCÃO, D. P.; BARROS FILHO, G.; NISHIDA, N. K.; BORGES, S. R. Exame microbiológico de sorvetes não pasteurizados. Revista de Saúde Pública, São Paulo, v. 17, n. 1, p. 2-8, fev. 1983.

FANTUZZI, E.; PUSCHMANN, R.; VANETTI, M. C. D. Microbiota contaminante em repolho minimamente processado. Ciência e Tecnologia de Alimentos, São Paulo, v. 24, n. 2, p. 207-211, abr./jun. 2004.

ICMSF. Guidelines for the microbiological examination of ready-to-eat foods. Sydney: Commission on Microbiological Specifications for Foods, 2001. 5 p.

KUMAR, C. G.; ANAND, S. K. Significance of microbial biofilms in food industry: a review. International Journal of Food Microbiology, Amsterdam, v. 42, p. 9-27, June 1998.

LOPES, P. S. N.; SOUZA, J. C.; REIS, P. R.; OLIVEIRA, J. M.; ROCHA, I. D. F. Caracterização do ataque da broca dos frutos do pequizeiro. Revista Brasileira de Fruticultura, Jaboticabal, v. 25, n. 3, p. 540-543, dez. 2003. 
MELO JÚNIOR, A. F.; CARVALHO, D.; PÓVOA, J. S. R.; BEARZOTI, E. Estrutura genética de populações naturais de pequizeiro (Caryocar brasiliense Camb.). Scientia Forestalis, Piracicaba, n. 66, p. 56-65, dez. 2004.

MINAS GERAIS. Decreto n. 42646, de 5 de junho de 2002. Regulamenta a Lei n. 13965, de 27 de julho de 2001, que cria o programa mineiro de incentivo ao cultivo, à extração, ao consumo, à comercialização e à transformação do pequi e demais frutos e produtos nativos do cerrado. Belo Horizonte: Diário Oficial do Estado de Minas Gerais, 2002.

NGUYEN-THE, C.; CARLIN, F. The microbiology of minimally processed fresh fruits and vegetables. Critical Reviews in Food Science and Nutrition, London, v. 34, n. 4, p. 371-401, Apr. 1994.

OPAS. HACCP: instrumento essencial para a inocuidade de alimentos. Buenos Aires, 2001.

\section{PINHEIRO, N. M. S.; FIGUEIREDO, E. A. T.;} FIGUEIREDO, R. W.; MAIA, G. A.; SOUZA, P. H. M. Avaliação da qualidade microbiológica de frutos minimamente processados comercializados em supermercados de Fortaleza. Revista Brasileira de Fruticultura, Jaboticabal, v. 27, n. 1, p. 153-156, abr. 2005.

PINTO, U. M.; CARDOSO, R. R.; VANETTI, M. C. D. Detecção de Listeria, Salmonella e Klebsiella em serviço de alimentação hospitalar. Revista de Nutrição, Campinas, v. 17, n. 3, p. 319-326, jul./set. 2004.
POZO, O. V. C. O pequi (Caryocar brasiliense): uma alternativa para o desenvolvimento sustentável do cerrado no Norte de Minas Gerais. 1997. $100 \mathrm{f}$. Dissertação (Mestrado em Administração Rural) Universidade Federal de Lavras, Lavras, 1997.

RODRIGUES, K. L.; GOMES, J. P.; CONCEIÇÃO, R. C. S. Condições higiênico-sanitárias no comércio ambulante de alimentos em Pelotas-RS. Ciência e Tecnologia de Alimentos, Campinas, v. 23, n. 3, p. 447-452, set./dez. 2003.

SALUSTIANO, V. C.; ANDRADE, N. J.; BRANDÃO, S. C. C.; AZEVEDO, R. M. C.; LIMA, S. A. K.

Microbiological air quality of processing areas in a dairy plant as evaluated by the sedimentation technique and a one-stage air sampler. Brazilian Journal of Microbiology, São Paulo, v. 34, n. 3, p. 255-259, July/ Sept. 2003.

SIQUEIRA, M. I.; GERALDINE, R. M.; QUEIROZ, K. S.; TORRES, M. C. L.; SILVEIRA, M. F. A. Conserva de pequi. Goiânia: UFG, 1997.

TORREZAN, R.; EIROA, M. N. U.; PFENNING, L. Identificação de microrganismos isolados em frutas, polpas e ambiente industrial. Boletim CEPPA, Curitiba, v. 18, n. 1, p. 27-38, jan./jun. 2000.

WORLD HEALTH ORGANIZATION. Food safety and foodborne illness. Disponível em: <http://www.who.int imediacentre/factsheets/fs $237 / \mathrm{en} /$ print.htmly. Acesso em: 12 jul. 2006. 